\title{
Organization of Cardiosurgical Care for Children with Congenital Heart Diseases in Children Under One Year with Determination of Risk Factors of Surgical Treatment
}

\author{
Berkin Turkulov ${ }^{1,2 *}$, Altyn Aringazina ${ }^{1,2}$, Vitali Pak ${ }^{3}$, Kairat Kuatbekov ${ }^{1}$, Nurlan Baizhigitov ${ }^{1}$
}

\author{
${ }^{1}$ Kazakhstan's Medical University “KSPH”, Almaty, 050060, KAZAKHSTAN \\ ${ }^{2}$ Center of Perinatology and Pediatric Cardiac Surgery, Almaty, 050000, KAZAKHSTAN \\ ${ }^{3}$ Fondazione Toscana G. Monasterio, Via Aurelia Sud, Massa, 54100, ITALY \\ *Corresponding Author: berkin86@mail.ru
}

Citation: Turkulov B, Aringazina A, Pak V, Kuatbekov K, Baizhigitov N. Organization of Cardiosurgical Care for Children with Congenital Heart Diseases in Children Under One Year with Determination of Risk Factors of Surgical Treatment. Electron J Gen Med. 2021;18(5):em315. https://doi.org/10.29333/ejgm/11141

\section{ARTICLE INFO}

Received: 24 Jan. 2021

Accepted: 3 Jul. 2021

\begin{abstract}
Background: Congenital heart defects are represented by numerous nosological forms. Today is known to be more than 90 variants of congenital heart defects (CHD) and their combinations. In the structure of the CHD 1st place occupies the defect of the interstitial septum, which according to various authors is $30-50 \%$ of all congenital defects of the heart, 2nd place - open arterial duct (10\%), defect of the interstitial artery, interstitial defect, tetrad Fallo, transposition of main vessels, atrioventricular communication do not exceed 5-7\% of each defect. The share of the remaining congenital malformations of the heart is less than $1-2 \%$.
\end{abstract}

Aim: To study the factors of the condition and organization of cardiac surgery to children with congenital heart defects Center for Perinatology and Pediatric Cardiac Surgery.

Methods: From November 20, 2011 to December 29, 2018, the Center for Perinatology and Pediatric Cardiac Surgery treated 1,098 children aged 1 year, 175 of whom were newborns $(15.9 \%)$. Of the last 27 were restricted to conservative treatment. Eight (29.6\%) of these patients died from hypoxia and / or cardiac insufficiency, which were incompatible with life, as well as from congenital pathology of other organs and systems. In the remaining $148(81.7 \%)$ cases, various surgical interventions were performed.

Results: The comparison of the risk group shows that there was no difference between them in the structure of the main critical CHD. He drew attention to the fact that the increase in the number of risk factors (RF) was associated with an increase in the number of obstructive lesions of the left ventricle and aortic arch. The difference between the groups RF (0) - RF (3), RF (0) - RF (4), RF (2) - RF (3) and RF (2) - RF (4) according to the number of these patients was reliable $(r)<0.05)$. Thus, this pathology was the most dangerous in relation to the accompanying problem. As the number of risk factors increased naturally, the number of patients in the corresponding groups decreased, and the level of mortality increased. Considering all the variants of the outcome (recurrence of postoperative complications, lethality), the most weighted isolated risk factors were "artificial ventilation", " intrauterine infection" and "Inconsistency", with the exception of the 2nd, 2nd and 3rd versions, respectively. 59.9 times. The most dangerous in this aspect are "Syndromes", "GIEP".

Conclusion: Risk factors are predictors of specific postoperative complications: outbreaks of encephalopathy occur in cerebral complications in $5.4 \%$ of newborns, intrauterine infection, $30 \%$, and $30 \%$ of coronary heart disease. Assessment of the significance of the origin of non-surgical factors determines the most "weak link", and proves the necessity of the mandatory use of algorithms and protocols of individual congenital anomalies of congenital heart disease and congenital heart disease.

Keywords: risk factors, congenital heart defects, prenatal diagnosis, newborns

\section{INTRODUCTION}

Despite the success in the diagnosis and detection, problems with congenital heart defects, which are associated with a significant increase in the number of children with congenital defects, are often accompanied by a serious course of the disease (especially in young children), frequent occurrence of circulatory failure and high mortality. In all cases, surgical treatment and timely treatment.
In the last decade, the structure of cardiovascular diseases in children has undergone major changes, which is associated with a significant decrease in the frequency of rheumatic heart diseases, bacterial endocarditis and arrhythmias, the proportion of cardiomyopathy and congenital heart defects. The increase is due. On the one hand, it is widely used in the treatment of inflammatory heart diseases, on the other hand, it improves the diagnosis of functional pathology and affects the structural changes in the incidence [1]. 


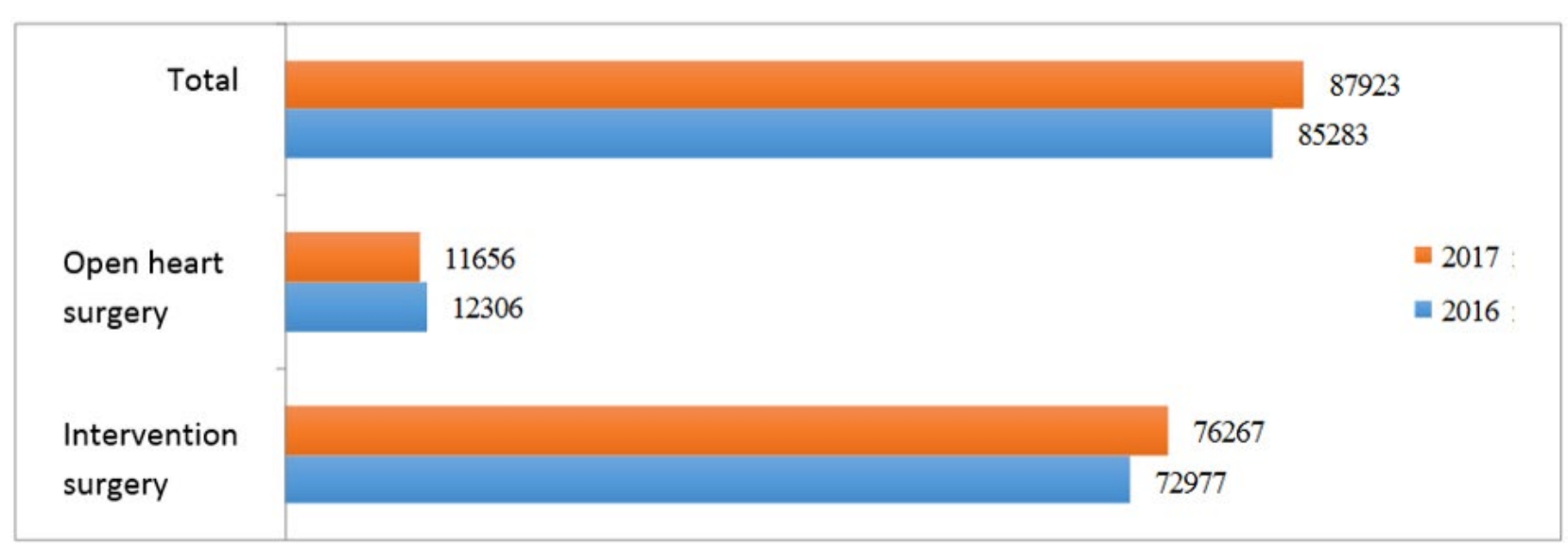

Figure 1. Total number of cardiac and interventional procedures in Kazakhstan, 2016

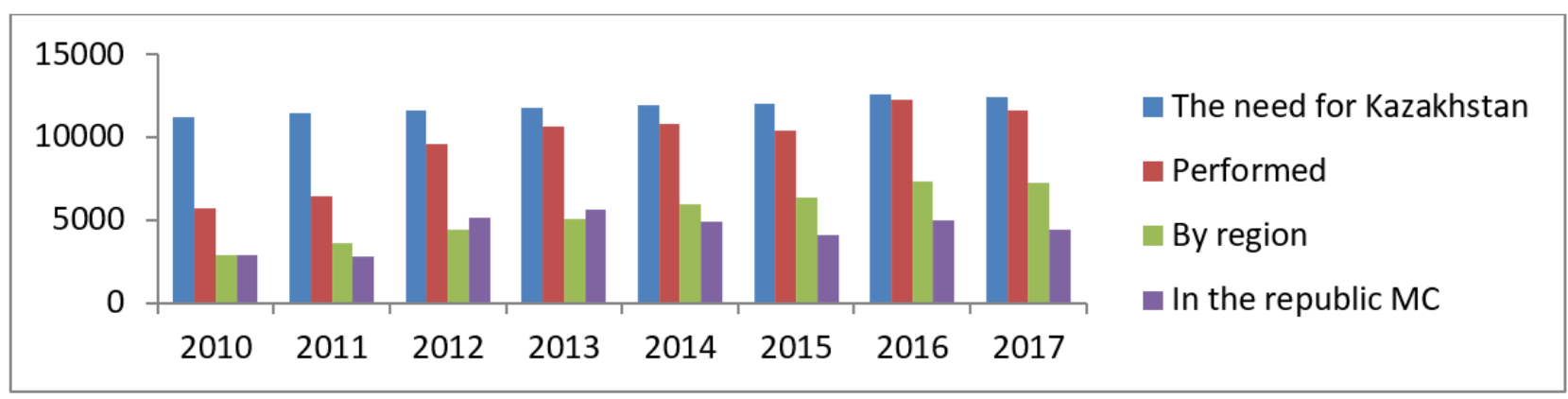

Figure 2. Fulfillment of the need for open heart surgery in Kazakhstan, 2010-2017

At the same time, a decrease in the quality of life and an increase in the number of harmful environmental factors created the prerequisites for increasing the frequency of congenital malformations in children. Congenital malformations are a serious problem in organizing their medical and social rehabilitation.

According to the operational data of the Republican Center for Electronic Health (Republican Electronic Medical Center), a total of 39 medical organizations (hereinafter referred to as the Moscow Region) perform cardiosurgical and interventional treatment of heart diseases in the republic. 4 private organizations and 2 departmental organizations (data from January 2017 to December 2017).

- Starting from 2017, the following services were created on the basis of medical institutions providing cardiac surgery services to the population.

- 629 cardiosurgical beds, including 483 beds for adults, and 146 beds for children;

- 69 cardiac resuscitation beds, of which 60 are beds for adults, and 9 are beds for children;

- 3377 cardiological beds, including 3128 beds for adults, and 246 beds for children;

- 324 interventional cardiological beds;

- 177 beds for rehabilitation treatment after cardiosurgical operations, including 133 beds for adults, and 44 beds for children;

- 438 beds for rehabilitation treatment of cardiological patients, including 408 beds for adults, and 30 beds for children;

In 2017, 11,656 open-heart operations were performed in the Republic of Kazakhstan (2016 - 12,306).
If the country's population needs 12,576 open heart surgeries (1,000 surgeries per 1 million adult population per year).

In 2017, 2051 operations were performed on children with congenital heart defects (hereinafter - CHD) in an open heart (2017 - 2306). In the republican medical organizations 1329 operations were performed, in the regions - 722 operations. The level of coverage of the population's need for CHD operations (7 operations per 1000 live births) for 2017 (January-December) amounted to 2870 operations, the fulfillment of the level of coverage needs amounted to $71.5 \%$.

Of the total number of operations for CHD for children:

- At the age of 15-17 years, 52 operations were performed, which is $2.5 \%$ of the total number of operations for children with CHD;

- At the age of 0 to 14 years, 1999 operations were performed, which is $97.5 \%$ of the total number of operations for children with CHD;

- Of these, $59.2 \%$, i.e., 1183 surgery was performed for children under 1 year old. Including 257 operations were performed by the newborn until the 28th day of life, the remaining 926 operations were performed on children from 28 days to 1 year of life.

Regional features of the prevalence of this group of diseases depend on the level of organization of prenatal diagnostics, the state of pediatric and cardiological care, the availability of modern equipment, specialists, the knowledge of neonatologists and pediatricians about the forms and characteristics of the course of congenital heart defects at different periods of the child's development [1]. 


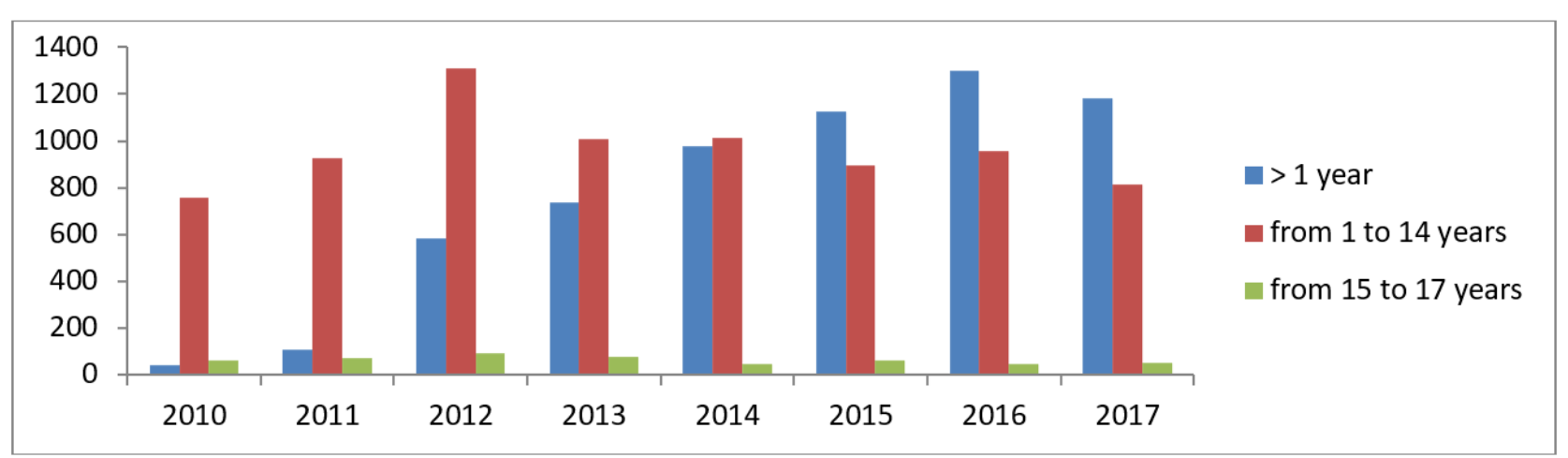

Figure 3. Total number of cardiac surgery for children with CHD by age group, Kazakhstan, 2010-2017

Congenital heart defects most often lead to death from congenital malformations in the first year of life $[2,4,11]$. In addition, they cause up to $40 \%$ of perinatal losses and $60 \%$ of deaths in the first year of life from congenital malformations [5]. The undoubted relevance of the problem is also due to the high mortality from diseases of this class.

The total mortality in CHD is extremely high, by the end of 1 week $29 \%$ of newborns die, by 1 month - 42\%, by 1 year $-87 \%$ of children [3]. The average term of death of most patients is 59 +73 days [6].

According to Burakovsky and Boqueria [4], various factors affect the survival of young children with CHD. It depends on the type of pathology. Depending on the severity of the lesion and the prognosis, $\mathrm{CHD}$ is divided into 4 diagnostic groups. The first group consists of malformations with a relatively favorable outcome (open ductus arteriosus, ventricular septal defect, ASD, pulmonary artery stenosis), in which natural mortality during the first year does not exceed $8-11 \%$; the second tetralogy of Fallot and myocardial disease (mortality 24-36\%); the third - Transposition of the great vessels, coarctation and stenosis of the aorta, atresia of the right atrioventricular opening, total abnormal lung drainage, the only ventricle of the heart, discharge of the aorta and pulmonary artery from the right ventricle, open atrioventricular canal (mortality 36-52\%).

The most severe course and poor prognosis are observed in CHD in patients with defects of the fourth group, which include hypoplasia of the left ventricle, atresia of the pulmonary artery with an intact interventricular septum, and the common arterial trunk. Fatal outcome in the first year of life occurs in 73$97 \%$ of such patients.

Another factor is the age of the patients at the time of the detection of the defect: the earlier hemodynamic disturbances occur, the more difficult and more severe the CHD. So, in the first week of life, left ventricular hypoplasia, transposition of the main vessels, TF, pulmonary atresia, aortic coarctation are manifested, while in the second half of life, $\mathrm{CHD}$ related to the first and second diagnostic groups are more common. Risk factors include extracardiac malformations, which are observed in $30 \%$ of children with CHD; if they are present, mortality increases to $36-89 \%$ [7].

The infant mortality rate due to circulatory abnormalities is currently 15.1 per 10,000 live births [9,20,21].

In the absence of intervention in children with congenital malformations of the blood circulation during the first year of life, 30 to $50 \%$ of newborns and infants die. The rest survive this critical age, but progressive heart failure and other complications of the disease lead to death in later childhood or severe disability [8].

The data of Russian specialists practically coincide with the data of foreign colleagues and the Republic of Kazakhstan $[1,4,17,18]$.

The medical and social significance of the problem is due to the fact that congenital heart defects affect the state of health of the child from birth, leading to disability. And disability has a huge socio-economic meaning:

1) the obvious economic damage to the state, expressed in the total cost of the lost working years of the person with disabilities, payment of rehabilitation measures and payment of disability benefits, as well as the diversion from social production of the labor potential of the mother of a disabled child or other person caring for him;

2) in addition, the social component of the problem of disability from childhood is great, expressed in the need for wide social adaptation of children and their parents $[10,15,16]$.

Summarizing the above, the need for preventing the birth of children with CHD and earlier detection of this pathology is obvious.

Congenital heart defects are represented by numerous nosological forms. To date, more than 90 variants of $\mathrm{CHD}$ and their combinations are known. In the structure of $\mathrm{CHD}$, the first place is taken by $\mathrm{CHD}$, which according to different authors accounts for $30-50 \%$ of all congenital heart diseases, the second place is by PDA (10\%), VSD, pulmonary artery stenosis, coarctation of the aorta, tetralogy of Fallot, transposition of the great vessels, atrioventricular communication does not exceed $5-7 \%$ for each of the defects $[8,10,11]$. The remaining congenital heart defects account for less than 1-2\%.

According to the results of other researchers, the second place after VSD is occupied by ASD, and the third - by PDA [3]. According to V.I. Burakovsky and L.A. Boqueria second place after VSD is TGA - 9-15\%, followed by TF - 8-13\% [4-9].

The frequency of various nosological forms of $\mathrm{CHD}$ in different age periods is different. This is due to high natural mortality in the initial period of life of a child with CHD. At the age of more than 2 weeks, such CHD, such as pulmonary atresia with an intact interventricular septum, hypoplasia of the left heart, and transposition of the great vessels are rarely observed $[4,16,17,19]$. 


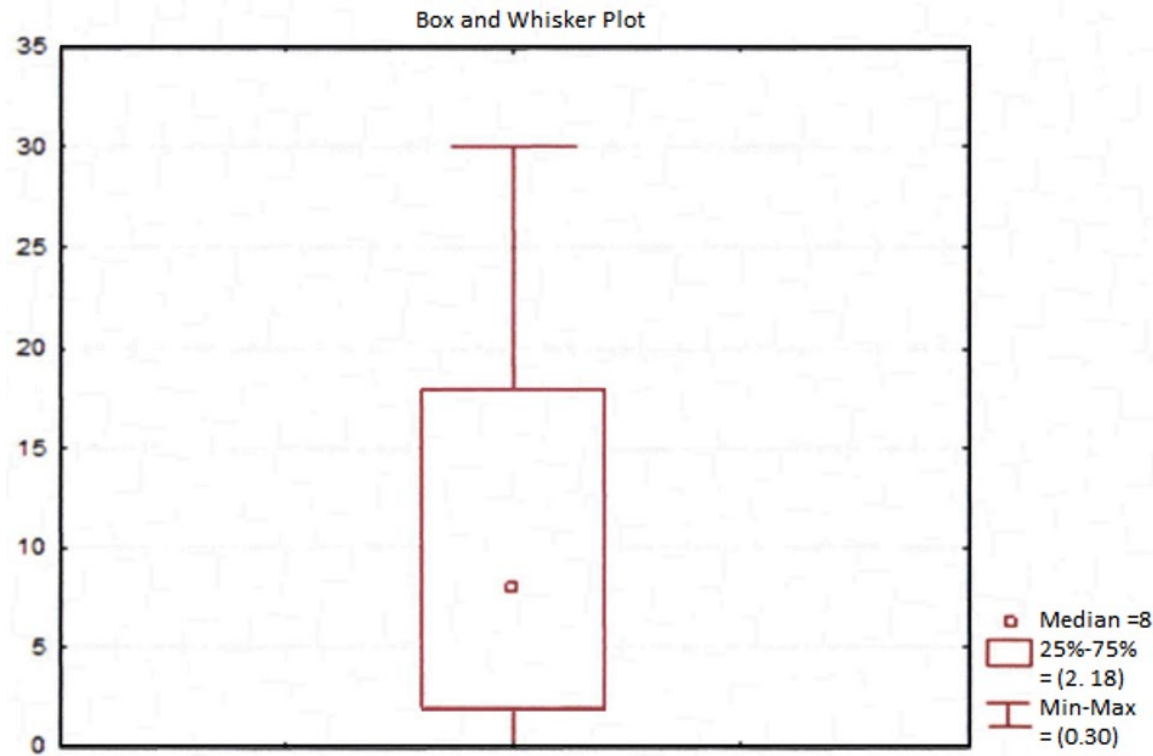

Figure 4. Age distribution of newborns with CHD at Perinatology and Pediatric Cardiac Surgery, Kazakhstan, 2011-2018

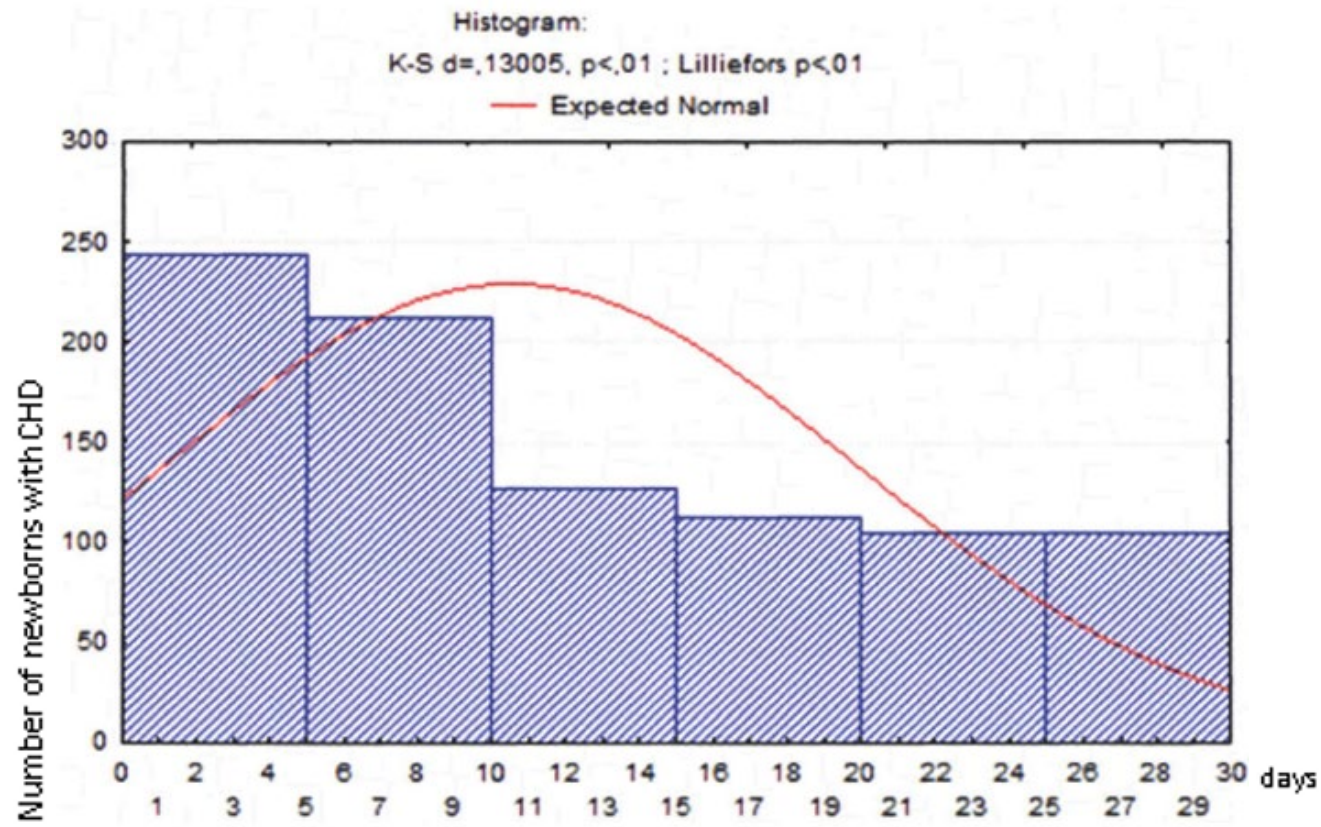

Figure 5. Age distribution of newborns with CHD at Perinatology and Pediatric Cardiac Surgery, Kazakhstan, 2011-2018

\section{Objective}

To study the state and organization of cardiac surgery for children with congenital heart defects at the Center for Perinatology and Pediatric Cardiac Surgery.

\section{MATERIALS AND METHODS}

From November 20, 2011 to December 29, 2018, the Center for Perinatology and Pediatric Cardiac Surgery treated 1,098 children under the age of 1 year, 175 of which were newborns (15.9\%). Of the last 27 were limited to conservative treatment. Eight (29.6\%) patients with hypoxia and / or heart failure who were incompatible with life, as well as from congenital pathology of other organs and systems. In the remaining 148 $(81.7 \%)$ cases, various surgical interventions were performed.

The median age of newborns was 8 days (2-18 days) (Figure 4).
Most patients are children in the first ten days of life (Figure 5). At the same time, 95 (54.2\%) children were included in the early neonatal group (life expectancy of up to 7 days). In this group, the average age of the children was $3.6 \pm 2.1$ days. The average body weight is $2.9 \pm 1.7 \mathrm{~kg}$ (0.9 to $5.1 \mathrm{~kg}$ ).

The median body weight of children throughout the study group upon admission to treatment was $3.25 \mathrm{~kg}$ (2.9-3.6) (Figure 6). 7.

The distribution of weight indicators is presented in Figure

The range of nosological forms of CHD diagnosed in newborns hospitalized for the period 2011-2018. presented in the table and distributed in accordance with the frequency of occurrence in descending order (Table 1). 
Box and Whisker Plot

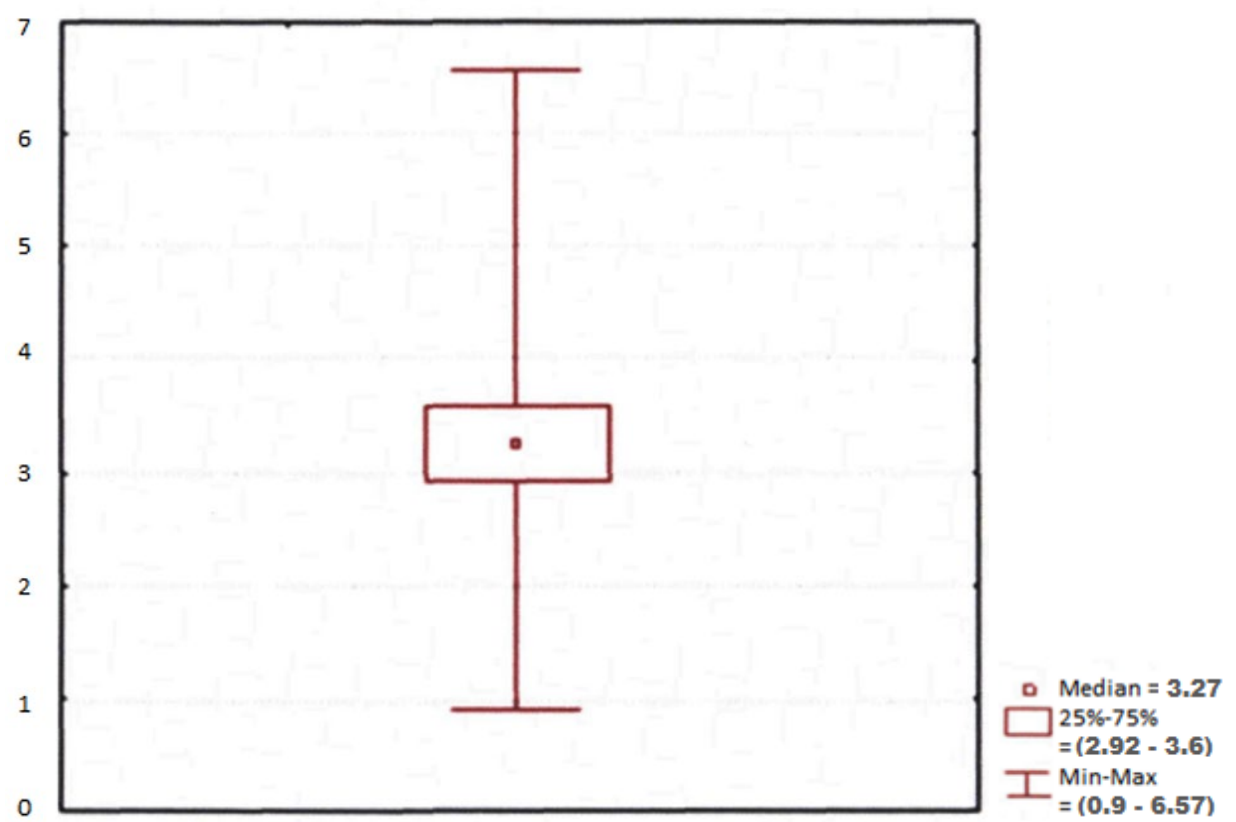

Figure 6. Body weight distribution of newborns with CHD at Perinatology and Pediatric Cardiac Surgery, Kazakhstan, 2011-2018

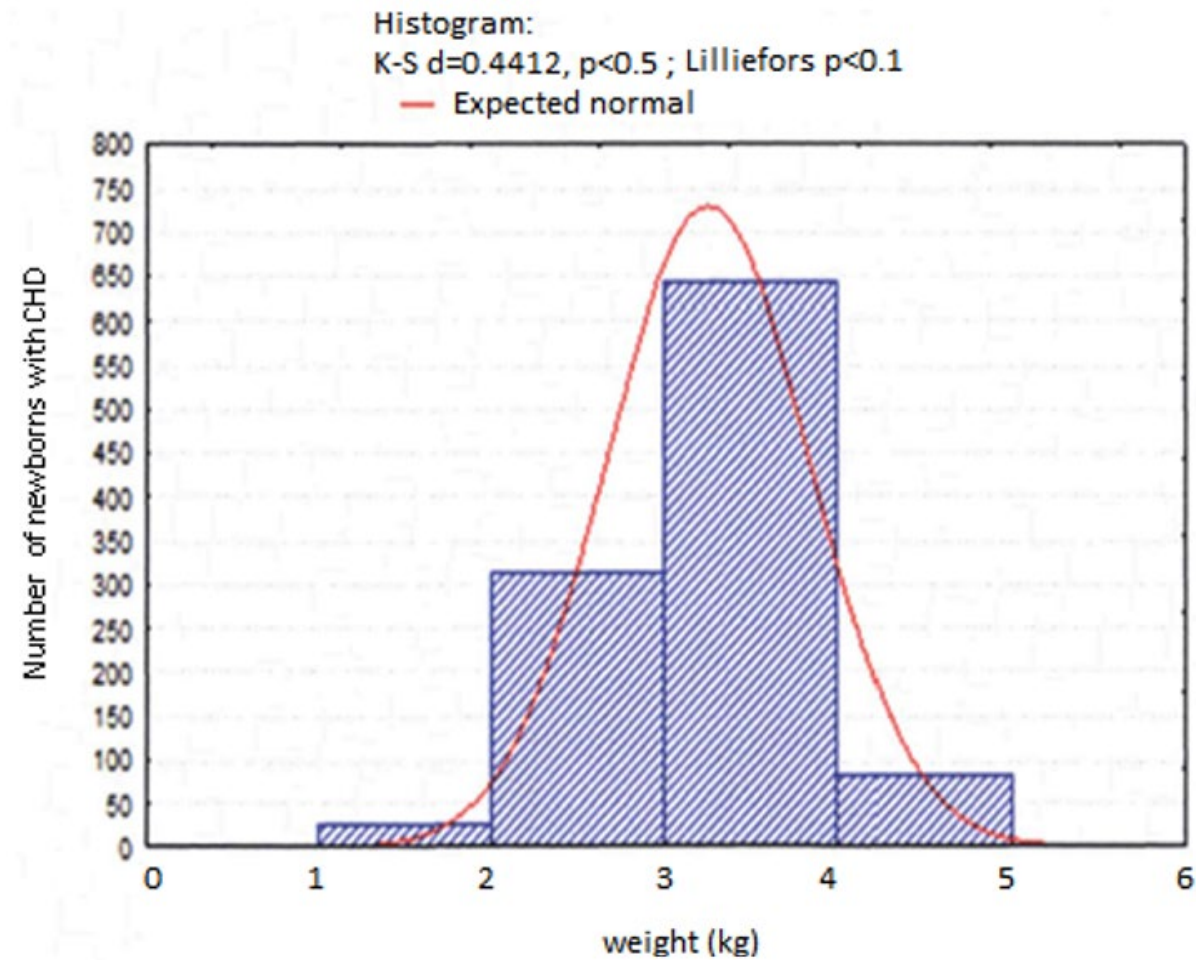

Figure 7. Body weight distribution of newborns with CHD at Perinatology and Pediatric Cardiac Surgery, Kazakhstan, 2011-2018

During the analysis, 148 newborns were operated on, and they underwent 157 different surgical procedures (an average of 1.06 per patient). Thirty-nine (26.3\%) patients underwent extracorporeal circulation (EK), of which $56(37.8 \%)$ underwent closed surgery, and 53 (35.9\%) underwent endovascular surgery. In addition, the nature of the operation amounted to $45.9 \%$ of newborns who underwent surgery $(n=68)$.

The strategy of surgical intervention depends on the condition of the patient, as well as on the anatomical and hemodynamic characteristics of the defect. More than half of the children (110-74.3\%) underwent surgery for emergency reasons. The diagnosis should determine if an intervention is required based on the clinical condition of the patient and the etiology of coronary heart disease. Catheter-dependent patients with coronary heart disease include: aortic transposition (TGA), left hypoplasia syndrome (HSLH), obstructive aortic arch disease (aortic coarctation, aortic arch interruption), lung atresia (APA), critical valve aorta, and pulmonary artery stenosis.

Depending on the type of intervention, the average age of the children differed statistically significantly $(p<0.001)$ : in the intravascular group, the average age was 2.9 days ( 1 to 17 days) 
Table 1. The spectrum of CHD in hospitalized newborns

\begin{tabular}{|c|c|c|}
\hline Diagnosis (primary) & $\%$ incidence & Abs. number (n) \\
\hline TGA, including Taussig Bing Anomaly & $19.8 \%$ & 29 \\
\hline Coarctation of the aorta & $16.8 \%$ & 25 \\
\hline $\begin{array}{l}\text { Atresia of the pulmonary artery with an intact interventricular septum (including } \\
\text { critical valvular pulmonary stenosis) }\end{array}$ & $6.7 \%$ & 10 \\
\hline Hypoplasia syndrome of the left heart & $2.1 \%$ & 3 \\
\hline APA with VSD & $6 \%$ & 9 \\
\hline CHD with heart abnormalities & $0.67 \%$ & 1 \\
\hline Critical Valvular Aortic Stenosis & $5.4 \%$ & 8 \\
\hline Aortic arch break & $6.7 \%$ & 10 \\
\hline TF (extreme form) & $7.4 \%$ & 11 \\
\hline $\mathrm{OVH}$ & $15 \%$ & 22 \\
\hline PDA & $7.4 \%$ & 11 \\
\hline Other congenital malformations and heart disease & $0.67 \%$ & 1 \\
\hline TADPV & $3.3 \%$ & 5 \\
\hline Common Arterial Trunk & $0.67 \%$ & 1 \\
\hline VSD & $1.35 \%$ & 2 \\
\hline Total & $100 \%$ & 148 \\
\hline
\end{tabular}

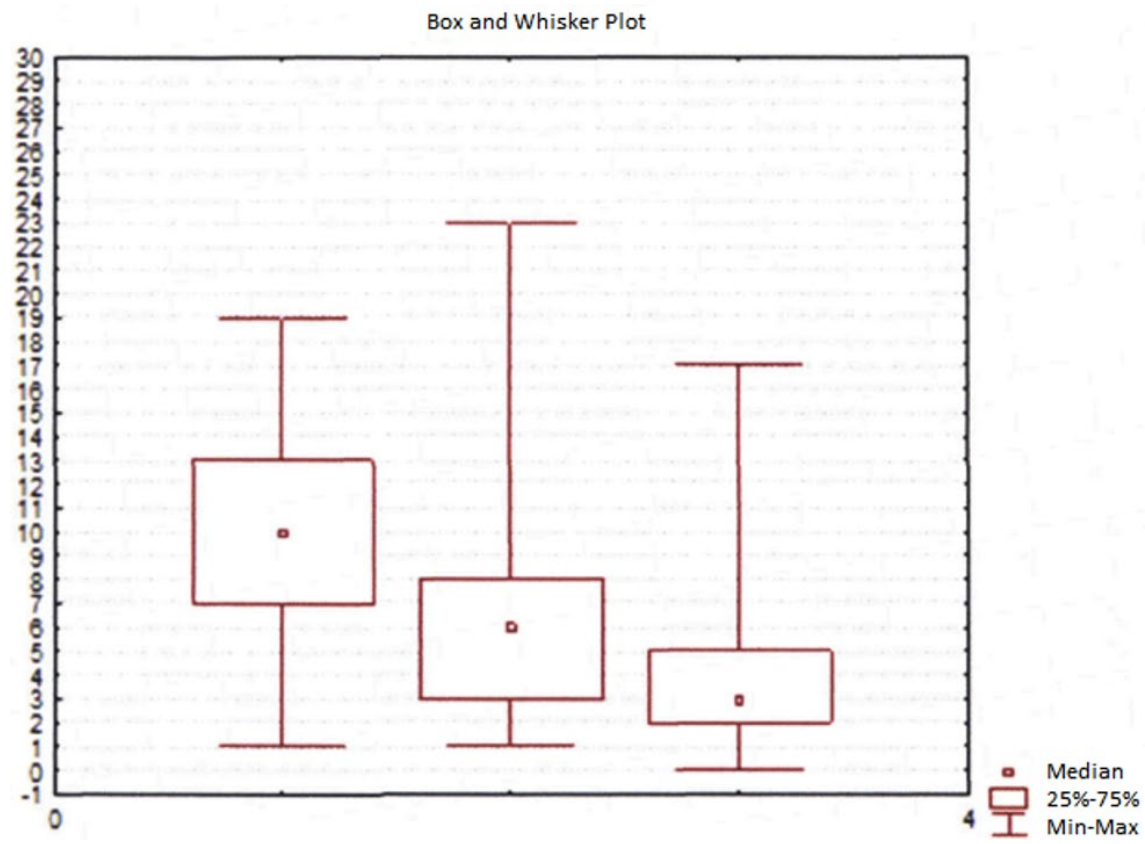

Figure 8. Distribution of children by age depending on the type of surgical intervention

using the closed method (without EK). In the EK group - 5.8 days (from 1 to 27 days) and -9.7 days (from 7 to 28 days) in the infrared mode (Figure 8).

The complexity and severity of the intervention was evaluated on an Aristotle scale [1]. The results of surgical treatment were analyzed during the first 30 days after surgery, taking into account adverse effects (patient death) and risk factors for postoperative complications.

\section{Statistical Methods}

Statistical processing and analysis of data was carried out using SPSS 21 and MS Excel.

\section{RESULTS}

Based on the analysis task, the Center for Perinatology and Pediatric Cardiac Surgery continuous treatment period was chosen in pediatric cardiac surgery, during which at least two thirds of the newborns experienced various concomitant diseases and complications during hospitalization. The date for this period is from November 20, 2011 to December 29, 2018. During this period, 1,098 children under the age of 1 year were treated, of which 175 were newborns (15.9\%). Of the last 27 were limited to conservative treatment. Eight (29.6\%) of these patients died from hypoxia and / or heart failure, which were incompatible with life, as well as from congenital pathology of other organs and systems. In the remaining 148 $(81.7 \%)$ cases, various surgical interventions were performed.

A comparative analysis of our data and the 10 most common disease research units in the STS database shows that CHD spectra in both databases of newborns are mainly characterized by severe defects: TGA, both simple and benign prostatic hyperplasia, obstructive aortic arch disease, critical valve aorta and pulmonary stenosis, pulmonary atresia, left ventricular dysplasia syndrome, etc. (Figure 9 and Figure 10) $[1,4,5,20]$.

Differences in the structure and frequency of occurrence of certain nosological forms among hospitalized newborns in the Center for Perinatology and Pediatric Cardiac Surgery 

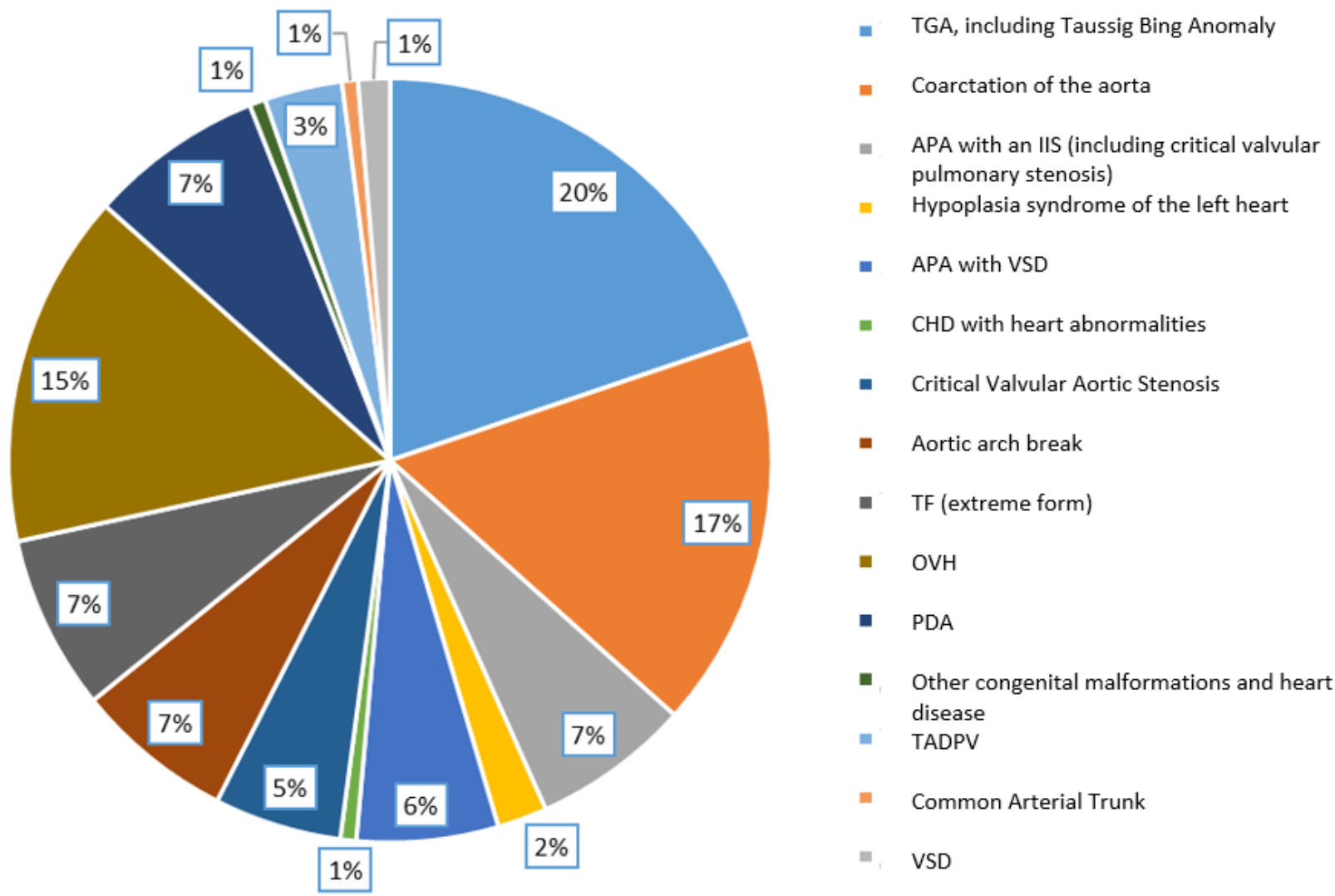

Figure 9. Distribution of CHD by nosology (Center for Perinatology and Pediatric Cardiac Surgery data for the period 2011-2018, $\mathrm{n}$ $=1098)$

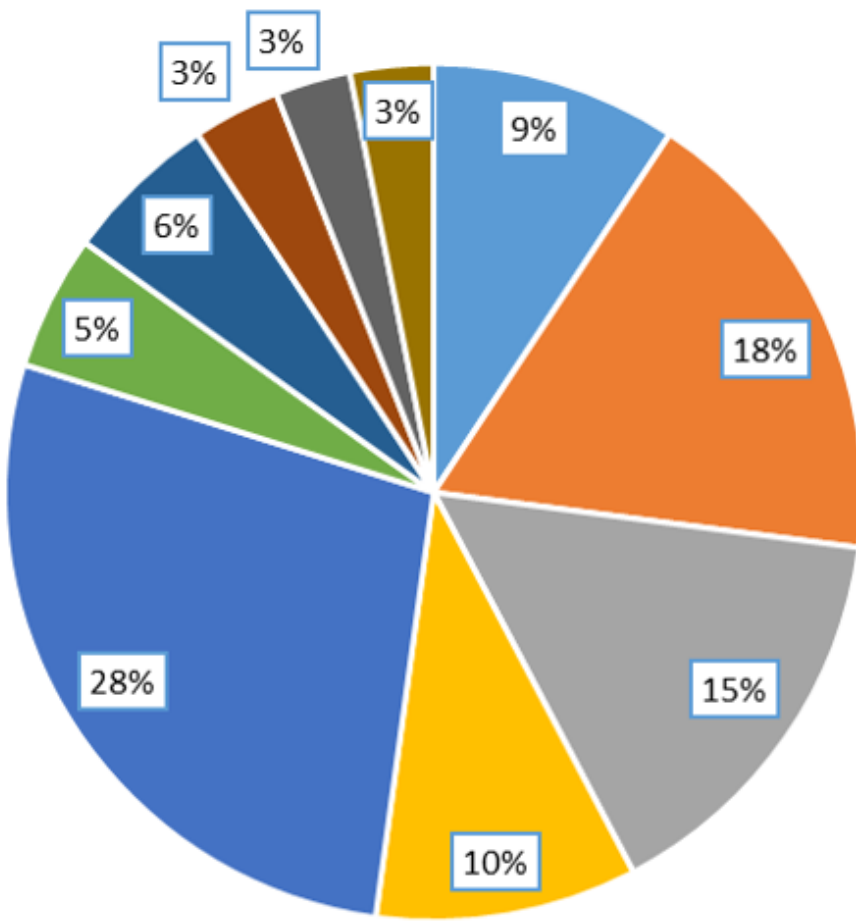

1. PDA
Hypoplasia syndrome of the
I left heart

Other congenital

II. malformations and heart disease

In Coarctation of the aorta

- TGA

TGA VSD

\section{Other congenital}

- malformations and heart disease

- $\quad$ APA with VSD

- $\mathrm{OVH}$

- Aortic arch break

Figure 10. Distribution of CHD by nosology (data from STS - American Society of Thoracic Surgeons for 2006-2010, $n=18585$ )

compared to foreign clinics can be explained by the peculiarities of the organization of surgical treatment. For example, in the United States, the majority of children with acute respiratory infections are operated on-site (resuscitation departments of premature infants), and newborns with more complicated diagnoses are sent to the Center for Perinatology and Pediatric Cardiac Surgery.

The severity of the condition of children upon admission to hospitalization is characterized by the following data: $34.5 \%$ of newborns had SO2 less than 50\%, while compensated metabolic acidosis (BE deficiency less than -7.5) occurred in 
$28.3 \%$, and decompensated ( $\mathrm{pH}$ less than 7.3 ) - in $36 \%$ of newborns. The state of hypoglycemia (glucose less than 3.5 $\mathrm{mmol} / \mathrm{l}$ ) was detected in $14.2 \%$ of cases.

Heart failure I degree was observed in $33.8 \%$ of newborns, IIA degree was detected in $30.9 \%$, IIB degree - in $21.0 \%$, III degree - in $14.3 \%$ of children.

\section{The Study of Risk Factors}

In order to assess the effect of various signs and groups of signs on the survival of patients and the postoperative course of the disease, we studied groups of parameters: anamnestic (gestational age, weight, height, gender, age at admission, concomitant somatic pathology), laboratory (positive signs of intrauterine infection, genetic forms and syndromic $\mathrm{CHD}$ ) and clinical (condition upon admission and the need for respiratory support, the presence of infusion of prostaglandins of group E1 (PGE), type and radicalism of surgical intervention, duration of treatment and features of the postoperative period). The endpoints of the analysis were indicators such as 30-day survival, complications of the postoperative period, mortality, total hospital bed length, hospital bed length in the intensive care unit and intensive care unit (ICU), and the duration of artificial ventilation after surgery.

Actually, surgical issues (accesses, options and types of operations), features of anesthesiology and perfusion therapy, features of the early postoperative period and the provision of resuscitation benefits were evaluated only collectively - on the Aristotle scale [2]. Thus, the expert assessment was focused mainly on the anamnestic, clinical, laboratory results of a study of children, as well as non-surgical reasons that affect treatment outcomes (including in accordance with the recommendations of STS and EACTS).

The subsequent univariate and cluster analysis made it possible to first select the 22 most statistically significant signs, and then form a group of 7 most significant non-surgical signs: gestational age (prematurity), weight loss (unweighted children - less than $3 \mathrm{~kg}$, and children with hypotrophy), syndromic forms of CHD and multiple congenital malformations, signs of intrauterine (intrauterine infection) and other infections, concomitant somatic diseases, a serious condition from birth to surgical treatment with the need for respiratory support (mechanical ventilation), hypoxic-ischemic encephalopathy.

A more detailed study of these factors showed that prematurity and low birth weight of children are combined with each other in $95.2 \%$ of cases, and therefore these two factors were combined into one risk group ("Prematurity"), Separate factor highlighted "Somatic." A wide range of extracardial pathology presented in newborns included in our study is given below in accordance with the problems encountered in the treatment and nursing in the perioperative period:

Anomalies in the development of the respiratory system (congenital stridor, congenital lung pathology) - prolong the time of artificial ventilation, after extubation they are manifested by severe bronchial obstruction with respiratory failure and an increased risk of re-intubation of the trachea, usually require massive antibacterial therapy.

Hernia and paresis of the diaphragm - the need for artificial ventilation before surgery, the development of respiratory failure, prolonged pneumonia, the need for additional operations;
Malformations of the intestinal tube (tracheoesophageal fistula, atresia of the duodenum, atresia of the anus and / or rectum, rectovaginal fistula, embryonic hernia, incomplete bowel rotation, omphalocele) - the need for initial surgical treatment of this pathology, in connection with which the correction of $\mathrm{CHD}$ was stabilized condition, or there was a need for simultaneous operations by several teams of surgeons, which significantly increased the duration of the operation;

Hemolytic disease of the newborn (HDN) - the need for targeted treatment in the early stages of life before surgical intervention for CHD and the operation of a replacement blood transfusion, which increases the risk of post-transfusion reactions after cardiac surgery with blood transfusion, anemia, significantly increases the risk of neurological complications and complicates the care of newborns generally;

Birth injuries (cephalohematomas, injuries of the cervical spine, paresis of the hands, collarbone fractures, torticollis) limit the possibility of manipulation with the newborn, and also increase the risk of neurological complications

The pathology of the development of the urinary system (doubling of the kidneys, hydronephrosis, dysplasia and dystopia of the kidneys, cryptorchidism, hypospadias, inguinal-scrotal hernia, dropsy of the testicle, inguinal and herniated cervical hernias) - predispose to infection of the urinary tract and early development of renal failure. The identification of such a pathology at the preoperative stage may delay the execution of heart surgery due to the need for additional examination of the patient. In turn, long-existing hypoxemia only contributes to the formation of vascular and non-vascular glomerular anomalies [11].

Maxillofacial malformations (congenital cleft soft and hard palate, upper lip), malformations of the musculoskeletal system, abnormalities of the hand and forearm (referred to the somatic, and not to the "Syndromes", because they were not confirmed by the results of genetic tests). Children with similar malformations experienced technical difficulties in ensuring adequate artificial ventilation and subsequent transfer to spontaneous breathing, and the placement of peripheral and central venous catheters;

Newborns with extracardiac abnormalities and laboratoryconfirmed genetic / chromosomal abnormalities were assigned to the Syndromes group.

The artificial ventilation group has combined premature and newborn babies hospitalized in a hospital with mechanical ventilation (artificial ventilation).

A significant representation of intrauterine infections and hypoxic-ischemic encephalopathy in the studied cohort made it possible to distinguish these nosologies into separate groups: "intrauterine infection".

Thus, six main risk factors were identified that had a different representation in the cohort of patients, and identified as follows (Table 2).

The role of the obtained six factors was investigated by the ROC analysis method (Figure 11). In the study of the obtained characteristic survival curve for newborns, the area under the ROC curve (AUC - area under curve) was 0.8073 (standard deviation $(\mathrm{SE})=0.02213)$, which confirms the proposed hypothesis on the role of non-surgical risk factors in the outcome of surgical treatment of newborns with CHD. 
Table 2. Frequency of occurrence of major risk factors (RF)

\begin{tabular}{|c|c|c|}
\hline Risk factors & Designation groups & Frequency in series (\%) \\
\hline Smallness and Prematurity & Prematurity & 31.2 \\
\hline Intrauterine infection and another infection & «Intrauterine infection» & 17.8 \\
\hline Syndromic forms of $\mathrm{CHD}$ and multiple vices development & "Syndromes" & 6.3 \\
\hline Related somatic diseases & «somatic» & 18.7 \\
\hline Artificial ventilation before surgery & «Artificial ventilation» & 9.9 \\
\hline Hypoxic-ischemic encephalopathy (HIEP) & «HIEP» & 42.1 \\
\hline
\end{tabular}

Note. intrauterine infection - intrauterine infection; artificial ventilation - mechanical ventilation

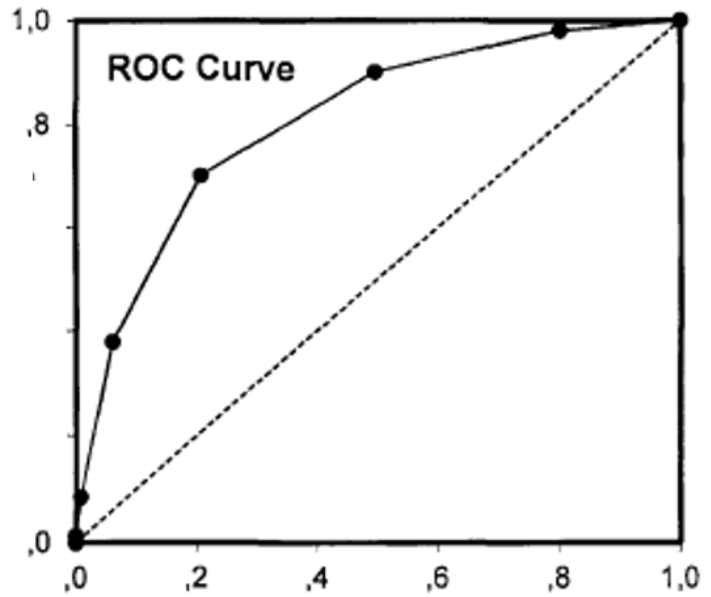

Figure 11. Characteristic curve (ROC-curve) of the survival rate of newborns taking into account the number of risk factors (from 0 to 6)

\section{Characteristic Groups}

In order to study the role of individual factors, as well as their combinations in the outcome of surgical interventions, the corresponding groups of patients were formed. Characteristics of the groups are given below.

\section{Group with no risk factors - RF (0)}

The group of children who did not have the above risk factors included 16 patients, including 10 (62.5\%) boys, 6 $(37.5 \%)$ girls. This group was subsequently used as a control.

The average age of the children was 6 days, weight $3.47 \mathrm{~kg}$, height $-52.0 \mathrm{~cm}$.

The main number of surgical interventions in this group was performed according to a closed procedure (7 operations) and the endovascular route ( 4 interventions), which accounted for $68.7 \%$ of all operations performed by a newborn of the RF group (0).

The average score on the Aristotle scale in the group was $8.1 \pm 3.5$.

Despite the fact that operations performed under cardiopulmonary bypass accounted for $31.3 \%$, the percentage of radical operations in this group of RF (0) was quite high $60 \%$.

The average time spent in ICU was 2 days, artificial ventilation - 1 day, total bed-day - 11 days.

The thirty-day survival rate among newborns without risk factors was $87.5 \%(n=14)$, and mortality - $12.5 \%(n=2)$.

\section{Group with one risk factor - RF (1)}

The largest group was the group, which included children with one risk factor. It was composed of 62 newborns, including $39(62.9 \%)$ boys, $23(37.1 \%)$ girls.

The average age was 7 days, weight $3.3 \mathrm{~kg}$, height $-51 \mathrm{~cm}$.

The main number of surgical interventions in this group was performed according to a closed methodology 22 (35.4\%). The number of operations with IR and endovascular procedures in this group was comparable (20 and 20 operations), which amounted to $32.3 \%$ and $32.3 \%$, respectively.

The average score for assessing the severity of interventions in the group was $8.3 \pm 3.6$.

The average time spent in ICU was 3 days, artificial ventilation - 1.5 days, total hospital bed - 13 days.

In this group, the 30 -day survival rate was $83.8 \%$, and the mortality rate was $16.2 \%$ (52 survived, 10 newborns died).

\section{Group with two risk factors - RF (2)}

The group with two risk factors included 29 babies, including 16 (55.1\%) boys, 13 (44.9\%) girls.

The average age was 9.0 days, weight $3.0 \mathrm{~kg}$, height $51 \mathrm{~cm}$.

The majority of surgical interventions in this group were performed according to an open technique $(n=27)$ and on a "closed" heart ( $n=2)$, which amounted to $93.1 \%$ of the total number of operations.

The average score for assessing the complexity of the performed interventions in the group was $8.4 \pm 4.1$.

In the RF group (2), as well as in the previous groups (RF (0) and RF (1)), the percentage of radical operations was significant $-48.2 \%$.

The average time spent in ICU was 3 days, artificial ventilation - 1.7 days, total hospital bed - 12 days.

In the presented group (RF2), there was a decrease in 30day survival rate, which was $75.8 \%$, while mortality increased to $24.2 \%$ ( 22 survived, 7 newborns died).

\section{Group with three risk factors - RF (3)}

The group with three risk factors included 23 babies, including 13 (56.5\%) boys, 10 (43.5\%) girls.

The average age was 10.0 days, weight $2.8 \mathrm{~kg}$, height - 50 $\mathrm{cm}$.

All operations among newborns with three risk factors were performed according to an open method.

The average score for assessing the severity of surgical interventions in the group was $8.7 \pm 4.2$.

In the FR group (3), radical interventions predominated, which amounted to $56.6 \%$, while palliative interventions $43.4 \%$. 
The average time spent in ICU was 5 days, artificial ventilation - 2.9 days, total hospital bed - 11 days.

There is a significant decrease in survival in the RF group (3) to $56.5 \%$ (13 newborns survived). 30-day mortality increased significantly and amounted to $43.5 \%$ (10 babies died).

\section{Group with four risk factors - RF (4)}

The group with four risk factors included 15 newborns, including 8 (53.3\%) boys, 7 (46.7\%) girls.

The average age was 10.3 days, weight $2.8 \mathrm{~kg}$, height $49 \mathrm{~cm}$.

All operations among newborns with four risk factors were performed according to an open method.

The average severity of the performed surgical interventions in the group was $8.9 \pm 3.2$ points.

Radical operations prevailed, accounting for 11 (60\%).

The average time spent in ICU was 5 days, artificial ventilation - 3.2 days, total bed-day - 9 days.

In the RF group (4), there was a tendency to a decrease in survival and an increase in mortality in the 30-day period after the operation: 5 survived and 10 newborns died, which in percentage terms is $33.4 \%$ and $66.6 \%$, respectively.

\section{A group with five or more risk factors - RF (5+)}

This group (with five or more risk factors) was made up of 3 newborns, among which 2 were boys and 1 was a girl.

The average age was 4 days of life, weight - $2.65 \mathrm{~kg}$, height $48 \mathrm{~cm}$.

Considering that for every newborn included in this group, all or almost all of the studied non-surgical factors were presented, and their condition was characterized by an extreme severity upon admission, surgical interventions were performed according to vital indications, which did not allow children of this group to perform complex reconstructive operations.

The average score on the Aristotle scale in the group was $7.7 \pm 4.6$.

Radical operations in the group amounted to only $33.3 \%$, which is significantly lower compared to other groups.

The average time spent in ICU was 3 days, artificial ventilation - 2 days, total hospital bed - 4 days.

30-day survival in the group did not exceed 33.3\%, 1 newborn survived. In the FR group (5+) mortality prevailed $66.7 \%$ ) (2 newborns died).

\section{Comparative Characteristics of Risk Groups}

A comparison of risk groups shows that there was no significant difference between them in the structure of the main critical CHD.

Attention was drawn to the fact that an increase in the number of risk factors was combined with an increase in the number of obstructive lesions of the excretory part of the left ventricle and the aortic arch. The difference between the groups RF (0) -RF (3), RF (0) -RF (4), RF (2) -RF (3) and RF (2) -RF $(4)$ in the number of these patients was significant $(p<0.05)$.

Thus, this pathology was the most dangerous in relation to concomitant problems.

With an increase in the number of risk factors, the number of patients in the corresponding groups naturally decreased, and the mortality rate increased.
Considering all outcome options (occurrence of postoperative complications, mortality), the most significant isolated risk factors were artificial ventilation, intrauterine infection, and Prematurity, in which the likelihood of death increased by 2.6-6.2 times, and complications - by 1.5-9.9 times. The least dangerous in this aspect are "Syndromes", "HIEP" and "Somatica".

\section{CONCLUSIONS}

In the group of newborns operated on for congenital heart defects, all nosological forms are presented, but the most common (87.9\%) are transposition of the main arteries, obstructive lesions of the aortic arch, various types of atresia of the pulmonary artery, critical valve stenosis of the aorta and pulmonary artery and $\mathrm{CHD}$ with hypervolemia of the pulmonary circulation. These defects, being "critical", are combined with a high frequency with various non-surgical risk factors ( $71 \%$ of patients).

The main non-surgical factors determining the severity of the condition of a newborn with "critical" congenital heart defects are preterm infants, intrauterine infections, hypoxicischemic encephalopathy, syndromic / genetic pathology, and factors partially associated with inadequate primary therapy and infant transport (artificial ventilation, somatic pathology).

When analyzing isolated factors, "artificial ventilation" in the preoperative period is the main predictor of the risk of postoperative complications (up to 64\%) and death (up to $40 \%)$.

The combination of congenital heart defects with risk factors determines the rapid decompensation of the condition and an unfavorable prognosis, regardless of the nosological form of $\mathrm{CHD}$ and the complexity of the intervention, rated on the Aristotle scale. The greatest number of risk factors can be expected with obstructive lesions of the aorta and excretory tract of the left ventricle.

With a combination of risk factors, the role of each of them increases. An avalanche-like worsening of the outcome is observed for three or more factors in one newborn: mortality significantly increases from $11.2 \%$ to $47.4 \%$, the duration of intensive care increases on average from 3.5 to 7.5 days and, as a result, financial costs increase for nursing babies.

Risk factors are predictors of specific postoperative complications: initial encephalopathy occurs in brain complications in $5.4 \%$ of newborns, intrauterine infections are accompanied by renal failure and pneumonia in $30.3 \%$ and $39.4 \%$ of children, respectively. Assessment of the significance of the initial non-surgical factors determines the "weakest link", and proves the necessity of mandatory use of algorithms and protocols for individual management of newborns with congenital heart defects in maternity hospitals and intensive care units of a cardiosurgical hospital.

The introduction of a differentiated approach to the treatment of newborns with risk factors before and after heart surgery and new management algorithms for this category of patients significantly reduces both overall mortality and the risk of developing major postoperative complications (pneumonia, ulcerative necrotic enterocolitis, renal failure), especially in groups "intrauterine infection" and "artificial ventilation". 
Author contributions: All authors have sufficiently contributed to the study, and agreed with the results and conclusions.

Funding: No funding source is reported for this study.

Declaration of interest: No conflict of interest is declared by authors.

\section{REFERENCES}

1. Kuatbekova KN. Data from the report of the chief freelance pediatric cardiac surgeon in Almaty.

2. Bespalova ED, Bokeriya EL. «Perinatal cardiologic screening» - methodical recommendations for neonatologists, pediatricians, obstetricians, gynecologists, and general functional diagnostics doctors. Voprosy prakticheskoy pediatrii. 2010;5(1):60-2. (In Russian).

3. Bokeriya LA, Gudkova RG. Cardiovascular surgery- 2011. Diseases and congenital anomalies of circulatory system. Moscow: A.N. Baculev Research center for cardiovascular surgery RAMS; 2012. 196 p. (In Russian).

4. Bokeriya LA, Tumanyan MR, Anderson AG, Efremov SO, Butrim EV, Chechneva VV, et al. Treatment and diagnostic algorithms for congenital heart diseases. Detskie bolezni serdtsa i sosudov. 2008;(2):20-8. (In Russian).

5. Bokeriya LA, Tumanyan MR, Bespalova ED. The system of perinatal care to newborns with critical congenital heart diseases: tendencies of development in the world practice and the state of the problem in Russia, particularly in the Central Federal District. Detskie bolezni serdtsa i sosudov. 2009;(3):3-11. (In Russian).

6. Health-2020: the basis of European policy in support of actions of the state and society to the benefit of health wellbeing. 2012. Available at: http://www.euro.who.int/ __data/assets/pdf_file/0011/170687/RC62wd08-Rus.pdf (in Russian).

7. Kassirskiy GI, Zotova LM. Rehabilitation of patients after surgical treatment of congenital heart diseases. Moscow: A.N. Baculev Research center for cardiovascular surgery RAMS; 2007. p. 136. (In Russian).

8. Kassirskiy GI, Rogova TV, Ivanova OI, Remezova TS, Nevedrova MN, Bazilevich MS. Clinical and functional state of children who had surgery for aortic coarctation in the first year of life, Detskie bolezni serdtsa i sosudov. 2010;(3);19-23. (In Russian).

9. On the basis of health protections for citizens of the Russian Federation: the Federal Law № 323-FZ of November 21, 2011 (revised and supplemented). Available at: http://base.garant.ru/12191967/ (In Russian).

10. On approval of the state program of the Russian Federation "Development of healthcare": Regulation of the Government of the RF of April 15, 2014;294. Available at: http://www.rg.ru/2014/04/24/zdravooxr-site-dok.html (in Russian).
11. On approval of the nomenclature of positions for medical and pharmaceutical personnel: the Order of the Ministry of Health of the Russian Federation of December 20, 2012 №1183t. 2013. Available at: http://www.rg.ru/2013/ 03/27/nomenklatura-dok.html (In Russian).

12. On approval of the procedure for providing obstetric and gynecological care: the Order of the MoH\&SD of the RF of October 2, 2009 № 808n. 2009. Available at: http://www.garant.ru/products/ipo/prime/doc/12072455/ (In Russian).

13. On the national strategy of actions in favor of children for the period of 2012 - 2017: the Decree of the President of the Russian Federation № 761 of June 01, 2012. Available at: http://base.garant.ru/70183566/ (In Russian).

14. On the procedure of organization of medical rehabilitation: the Order of the Ministry of Health of the RF of December 29 2012 № 1705n. 2012. Available at: http://www.rg.ru/ 2013/04/25/reabilitation-dok.html (in Russian).

15. Development of health care: the State Program of the Russian Federation. 2014. Available at: http://base.garant.ru/70643470/ (in Russian).

16. Simakhodskiy AS, Romanenko OP, Verlinskaya DK, Kuznetsova EYu. The role of congenital diseases and congenital malformations in children disability and possible ways of prevention. Voprosy prakticheskoy pediatrii. 2008;3(4):82-5. (In Russian).

17. Sokolova NA. Organization of medical rehabilitation in the Russian Federation: the legal aspects. Pravovye voprosy v zdravookhranenii. 2013;(9):26-34. (In Russian).

18. Garne E. Congenital heart defects: occurrence, surgery and prognosis in a Danish county. Scand. Cardiovasc. J. 2004;38:357-62. https://doi.org/10.1080/14017430410024 379 PMid: 15804803

19. Go AS, Mozaffarian D, Roger VL, Benjamin EJ, Berry JD, Blaha MJ, et al. Heart disease and stroke statistics-2014 Update: A report from the American Heart Association. Circulation. 2014;129:e28-e292. https://doi.org/10.1161/ 01.cir.0000441139.02102.80

20. Hoffman JI, Kaplan S. The incidence of congenital heart disease. J. Am. Coll. Cardiol. 2002;39:1890-1900. https://doi.org/10.1016/S0735-1097(02)01886-7

21. Lane DA, Millane TA, Lip GYH. Psychological interventions for depression in adolescent and adult congenital heart disease. Cochrane Heart Group Published Online: 28 Oct 2013. https://doi.org/10.1002/14651858.CD004372.pub2 PMid:24163137

22. Mitchell SC, Korones B, Berendes W. Congenital Heart Disease in 56,109 Births Incidence and Natural History. Circulation. 1971;43:323-32. https://doi.org/10.1161/01.CIR .43.3.323 PMid:5102136

23. Tikkanen AU, Oyaga AR, Riaño OA, Álvaro EM, Rhodes J. Paediatric cardiac rehabilitation in congenital heart disease: a systematic review. Cardiol. Young. 2012 Jun; 22(3):241-50. https://doi.org/10.1097/MAT.0000000000000 568 PMid:22251378 